\title{
More than the Curriculum: Teaching for Reconciliation in Western Australia
}

\author{
Sarah Booth, Bill Allen \\ Edith Cowan University \\ Western Australia
}

\begin{abstract}
In Australia, there are two dimensions to Indigenous education. The first and most widely discussed, is that of teaching Indigenous children and associated issues. The second is the teaching of Indigenous histories and cultures to all Australian children. This paper focuses on the teaching of Indigenous cultures and histories to non-Indigenous students by non-Indigenous teachers with a particular concern of education for Reconciliation. It explores how, and to what extent, schools are teaching Indigenous cultures and histories and the conceptualizations of Reconciliation. This in-depth case study revealed that there was real confusion in the two schools with regard to what is taught; how it is taught; who has responsibility; and what the nature of education for Reconciliation is about. However, the differences between the two schools suggest strongly that school culture, emanating from the Principal and the school's foundation, impact on the received curriculum which is not always as the curriculum of entitlement suggests or the intended curriculum expects.
\end{abstract}

\section{Introduction}

Evidence from historical State curricula suggest that very little attention was paid to teaching Western Australian secondary students about Indigenous histories and cultures prior to 1980 [8]. This reflected a lack of knowledge within the wider Australian community about Indigenous histories and cultures leaving long-standing, negative perceptions of Indigenous Australians unchallenged [18], [19].

There has, however, been extensive research into engaging and teaching Indigenous students, who on average fall two and a third years behind their nonIndigenous counterparts as explained in the Closing the Gap report [3]. Addressing this was a focus of 'Closing the Gap', a government policy to tackle poverty and related social issues within Indigenous communities [2]. Reconciliation, however, involves more than just improving the outcomes of Indigenous Australians; it involves a mutual understanding of each other by each other.

In Australia, there are ongoing discussions to improve the relationship between Indigenous and non-Indigenous Australians to promote Reconciliation [16], [17]. The school system is one obvious and important space where reform can take place; however, there are many obstacles preventing the intended, enhanced relationships from developing.

Throughout Australia's history there has been an unevenness in the way in which Aboriginal perspectives have been taught [10]. The focus in school History was on the European explorers, and Indigenous people only featured as threats or helpers [8]. There was little or no learning of Indigenous culture or perspectives. This has been gradually changing; and one recent development has seen the implementation of Reconciliation into the Australian Professional Standards for Teaching, which all teachers must adhere to.

Currently, there are two dimensions to teaching and learning about Indigenous cultures and histories. The first, which is more widespread in the available literature, focuses on improving Indigenous educational outcomes. The second involves teaching all Australians about Indigenous cultures and histories regardless of their background. Both dimensions are recognized by the Melbourne Declaration which outlines the education goals for young Australians and as such, is the curriculum of entitlement. The teaching standards which were introduced in Australia in 2013 also echo the Melbourne Declaration with the inclusion of two standards which explicitly relate to Indigenous students and Reconciliation [1]. These two standards state that all teachers must develop:

"1.4 Strategies for teaching Aboriginal and Torres Strait Islander students" and "2.4 Understand and respect Aboriginal and Torres Strait Islander people to promote reconciliation between Indigenous 
and non-Indigenous Australians" [1]. All new teachers must demonstrate these two standards and any teacher applying for a promotion must also be proficient at implementing them. How they are to do this is not specified within the standards themselves.

The curriculum of intent is the Australian Curriculum and the subsequent state variations of it, as these state what is to be taught in classrooms [13].

The cross-curriculum priorities (CCP) are a response to the Melbourne Declaration and designed "to equip young Australians with the skills, knowledge and understanding that will enable them to engage effectively with and prosper in a globalised world" [12]. They are to be embedded across all learning areas; however, despite the word 'priority' being used, the WA Curriculum states that, "Teachers may find opportunities to incorporate the cross-curriculum priorities into their teaching and learning programs. The cross-curriculum priorities are not assessed unless they are identified within the core content of the Western Australian Curriculum" [12].

However, teaching for Reconciliation has many challenges and obstructions. One of the biggest barriers is systemic racism, which is dangerous because it often goes unseen by the dominant culture. Systemic racism favors the dominant culture's instructional methods [11] by disadvantaging minority groups such as Indigenous Australians. Despite the constant iteration that Indigenous perspectives be taught to all students, there is still little understanding of how this is being implemented in schools, particularly those with few or no Indigenous students. This is evident from Maxwell's study where she surveyed pre-service teachers and found that they believed "the intended beneficiaries of the cross-curriculum priority were Aboriginal and Torres Strait Islander students or Aboriginal and Torres Strait Islander people more broadly" [13] (p.29). Therefore, there was a gap in the intended purpose of the CCP.

This paper reports on two case studies which explored the teaching and learning of Indigenous cultures and histories in two high schools in Western Australia. Data were collected from different tiers within the school including: the Principal, lead and classroom teachers, and a student focus group. By examining the different tiers of the school system, we were better able to understand how a school prioritizes the teaching and learning of Indigenous cultures and histories. As such, a symbolic interactionist viewpoint worked best for exploring the different perspectives. This understanding of the world is based on how our experiences shape how we respond to objects, people and events [6]. In the context of this study, how people interact with the teaching of Indigenous cultures and histories may have been impacted by lived experiences or new knowledge. It also incorporates the student perspective and how they interact with Indigenous peoples and the understanding of Indigenous cultures and histories.

\section{Reconciliation and constraints}

Reconciliation, as described by Reconciliation Australia, is a process of building mutual and respectful relationships between Indigenous and other Australians by eliminating 'gaps' in education, health and wellbeing, and addressing social disadvantages based on false beliefs and stereotypes [17]. The Australian government has been working to address many of these issues by developing a policy campaign of Closing the Gap. However, this is a complicated issue with many factors which impact not only how non-Indigenous people see Indigenous Australians but how Indigenous Australians see themselves and their perspectives of non-Indigenous Australians [20]. There are many psychological factors along with systemic factors which stall the process of Reconciliation.

The psychological factors comprise of stereotypes, false beliefs and prejudices. Stemming from these, the discriminations Indigenous people face consist of three different categories all involving violence against them. These include: direct violence; structural violence which impacts opportunities in life; and cultural violence "when the nation's attitudes and stereotypes ignore, justify and normalise such inequalities or blame them on the victims" [4] (p.201). Negative stereotypes of Indigenous people exist today despite evidence to contradict them. These active stereotypes are difficult to change because they have become part of the cultural knowledge. Even when someone from the minority group acts in a non-stereotypical way the stereotype persists because they are labelled an exception to the rule.

Balvin and Kashima argue that stereotypes are also more likely to be maintained when information that is consistent with cultural stereotype "is circulated in everyday discourse and more likely to be to be transformed when information that is inconsistent with the stereotype is shared" [4] (p.204). This puts great responsibility on schools to assist in challenging these stereotypes. Balvin and Kashima also states that "The onus to facilitate reconciliation should be with the 'settlers' who have caused the upheaval in Indigenous peoples' lives, yet it is often Indigenous Australians who drive this movement" [4] (p.213). Although it can be argued that non-Indigenous Australians are not doing enough to combat racism, there is evidence of a desire for change. This is based on the findings in this study which indicates the relationship between Indigenous and non-Indigenous Australians are of high importance for Australia. Also, there is a strong belief that all Australians should know about 
Indigenous culture and history, and lastly, evidence of the sharing of Australian values by the two groups [4] (p.214).

How to address this imbalance of Indigenous disadvantage is an issue which many are unsure of. This is partly due to a lack of knowledge of the roles white privilege and color blindness, and how these two things uphold systemic racism in the Australian community.

White privilege, which here refers to the situation of the Anglo-Saxon majority, often goes unexamined in Australia because white values and attitudes form the basis of mainstream views of "race and consequently shape the social interactions whites have with other whites and people of color in a variety of contexts" [5] (p.3). The cultural majority's ways and customs are therefore seen as 'normal' and every other culture is measured against it [13].

The danger of this 'invisible' and unexamined view of society is that whites claim their stereotypes and prejudices are not racial and that disadvantaged minorities are there by individual choice [7]. This colour blindness can be changed through increasing diversity awareness which improves white peoples' ability to explain how race plays a role in their lives.

\section{Teaching for Reconciliation}

The recent curriculum of entitlement, in place since 2008, and the curricula of intent (national and State) have been developed in a period of curriculum reform within the last two decades to enable all students to have a more inclusive education. The school and the classroom are envisaged as ideal spaces for effective implementation, but it may well be that it is school culture, which dictates the priorities of the school, impacts more heavily on the teaching and learning of Indigenous histories and cultures. Therefore, although these curricular documents have been created with the best intentions, they must be interpreted by the school and teacher before being received by their students. This interpretation becomes the enacted curriculum. Furthermore, the received curriculum, that which the students receive, is a culmination of the 'hidden curriculum' of the school culture and the enacted curriculum.

These five levels of curriculum have, wittingly or unwittingly, combined to address the inclusion of Indigenous cultures and histories, through the curriculum of entitlement, intent, enacted, hidden, and the received curriculum. The curriculum of entitlement is that which all young Australians have a right to. In furthering reconciliation, the Melbourne Declaration states that all young people should "Understand and acknowledge the value of Indigenous cultures and possess the knowledge, skills and understanding to contribute to, and benefit from, reconciliation between Indigenous and non-
Indigenous Australians [15]. The curricula of intent are the prescribed Australian Curriculum and Western Australian Curriculum. A significant policy decision in developing these curricula was to make the Indigenous histories and cultures component take the form of one of three cross-curriculum priorities, which were to be embedded across all learning areas and all years. Our findings reveal the unfortunate outcomes of what was a laudable intention. The enacted curriculum is when school leaders and teachers decide what aspects of, and how curricular elements, such as Indigenous cultures and histories, are to be taught and learned in the classroom. These decisions are largely based on the school priorities, often driven by school rankings in 'league tables' derived from the school's students' performances in standardized tests. Furthermore, schools and teachers are prone to focusing only on the content prescribed by the Western Australian curriculum. The laudable, but only suggested, parts of the curriculum, such as the cross-curriculum priorities, fall out of view, an ironic reflection of the state of Indigenous peoples in the community.

In the key learning areas such as Humanities and Social Sciences, where Indigenous perspectives should be most easily incorporated, there are a few prescribed topics that require teaching; otherwise addressing Indigenous histories and cultures are left to the whims of individual teachers or heads of learning areas.

Even with the implementation of the crosscurriculum priorities (CCP) included in both the Australian Curriculum and the WA Curriculum and which are suggested for inclusion across all learning areas, it this can become easy to avoid teaching IHC altogether.

How teachers are to implement these priorities is not specified, and as a result there has been much confusion among teachers across Australia explained in the Donnelly Wiltshire report (2014) as to the role and purpose of the CCPs [9]. Also many teachers were unwilling to embed these into their school syllabuses [9]. Those who understood the CCPs were quite critical of the effectiveness of such a broad approach to incorporate these priority areas. As the CCPs state that teachers 'may find opportunities' [my emphasis] for their implementation, an attitude arose that they only were implemented if it was easy to embed them or if it was manageable.

The teacher's personal choice and limited access to appropriate resources impacts the extent to which they teach Indigenous cultures and histories. As a result, the received curriculum can be quite distant from the more inclusive curriculum of entitlement. To gain insight into the enacted and received curriculum a study of two different schools was undertaken. 


\section{Methodology}

To understand in depth the factors which affect the teaching and learning of Indigenous cultures and histories, a multiple case study methodology was selected. Each case included interviews with the principal, lead and classroom teachers and a student focus group. By examining a cross-section of the school, a variety of perspectives on the factors which affect the teaching and learning of Indigenous cultures and histories could be gained.

The focus of this study was schools which had a disproportionately low number of Indigenous students as this might impact the presence or lack of community pressure on the teaching and learning of Indigenous cultures and histories. Much of the priorities in the education of Indigenous cultures and histories is to teach more effectively Indigenous students; however, little is known on the priority given to this area at schools with few or no Indigenous students. Therefore, a criterion for schools selected were the limited number of Indigenous students below the national population of $3 \%$.

Due to ethical considerations, participants were labeled into four groups; this was to prevent any profile from being built of any one participant from the quotes provided. Teachers were named 'Teachers' heads of learning area were labeled 'Lead teachers' and Principals and Deputy/Assistant Principals were labelled 'Executive teachers', However, students, who were part of a student focus group, and thus de-identified, remained simply 'Students'.

\section{Findings}

The responses of participants in two schools reported on in this paper revealed distinctly different approaches to the teaching of IHC. These differences, we will argue later in the discussion, reflect our initial hunch that school culture was a significant factor. However, there are interesting and important themes emerging from the interview data.

All the participants believed it was important to prioritize Indigenous perspectives; however, almost all acknowledged this priority was not reflected in their current teaching and learning programs and that more could be done. This was particularly evident at School A which did not celebrate NAIDOC (National Aboriginal and Islander Day Observance Committee) Week, other than it being mentioned at assembly. They cited the very low numbers of Indigenous students in the school, and their focus was instead on the broader, multicultural aspect of the school. This ties in with the widespread belief that Indigenous cultures and histories are solely for the education of Indigenous people. There was however, acknowledgment that it should become a priority.

In both schools, the Australian and WA curriculum stated what was to be taught in terms of IHC. However, the cross-curriculum priorities which are to be taught within schools where relevant are also expected to be implemented across learning areas. Yet, as to how and to what extent they are implemented were left up to individual teachers who admitted that it was easy to overlook this in favour of topics which, they argued had more resources.

This was evident in both schools where the topics within HASS appeared to be chosen based largely on the resources available. This affected how the CCP were implemented, in particular IHC. As there were already a few explicit units which included IHC such as Building a Nation and Rights and Freedoms, some teachers saw that as where the CCP fit and therefore, did not look for other areas to implement it. In fact, half of the teachers at this school were unsure of the purpose or understanding of the CCPs and mistook the CCPs for cross learning area teaching.

\subsection{School A}

The prevalent approach to the teaching and learning of IHC in School A were succinctly but ironically summarised by one Executive teacher: "Is it taught? Yes! Do we make it a priority? The answer would be no".

In School A, one teacher spoke about sticking closely to the content descriptors which explained what was to be taught. Their issue with the content descriptors was that teachers were expected to cover a large amount of information, and as a result, teachers said that they found it difficult to find the time to cover all that was required. "Well not in the depth that I think that we should be going into, because you just can't do it. It just would be impossible to, do each in depth" (Teacher). With this rush to 'fit everything in' it was clear that there was not the time to go into depth on the context surrounding rich issues such as the 1967 Referendum where Indigenous people were given citizenship rights.

"And even with the referendum you know there's they need to have an understanding of how Australians liberal system works which they don't and then you try to explain it and then they just get more confused so that they don't know really know what a referendum is or the significance of that but for most of the part they can kind of get what the events were like the freedom rides and what happened." (Teacher)

One Executive teacher also discussed that whatever was in the curriculum would be taught. However, as much of the IHC is left up to teachers' decisions around the embedding of the CCP, a school can easily implement the curriculum quite faithfully 
without spending much time giving attention to IHC. For example, Year 10, when the students are around 15 years old, is often the first time they learn any of these issues. When asked about what they had learnt about issues in the past, one student in the focus group remarked. "That they were actually treating people like that. It's a bit strange because now we're all equal, well there's still a bit of racism and stuff like that but it's fairly equal now" (Student). This also reflects the lack of contemporary issues that were taught in the school's curriculum; if they examined Closing the Gap a government policy which aims at combating Indigenous disadvantage and the sever inequalities, the student participants may have responded differently.

When asked what they would like to learn more about, the students answered that they had learnt about European settlement in the $18^{\text {th }}$ and $19^{\text {th }}$ centuries and the 'Stolen Generations' in the $20^{\text {th }}$ century but had learnt nothing about developments in between. "You've pretty much learnt the start, you skip like a lot of the middle part, and just the ending up until now" (Student).

In the past, this school had a close relationship with an Aboriginal community where Indigenous students would come to the school, with the result that there was greater empathy, at least, with the situations of some Indigenous people. However, this was an initiative of only one or two staff members and when they left the school, the program dissipated. With few Indigenous students at the school to prompt a continuation of prioritising IHC it was left up to teachers particularly those in HASS and English to implement IHC. The findings show that this was not actually happening.

One of the major findings from School A was that almost all participants had very little idea of what Reconciliation meant, and how the school could work towards it. There was confusion amongst the teachers as to what role they played in Reconciliation with members questioning their ability as non-Indigenous teachers to teach it. A Lead teacher discussed his uncertainty in the matter, "are we equipped as a teacher... Am I qualified to?". The teachers did say that they focused mainly on creating an awareness amongst the student body of IHC as a way of promoting Reconciliation. Nevertheless, the students themselves were unaware of the term and, when it was explained to them, and then asked what the school was doing to promote Reconciliation one student said, "It's not really doing much". The school leadership also talked about Reconciliation in terms of empowering Indigenous communities rather than speaking about what the school could do to promote reconciliation. "So for me to particularise the 'we acknowledge what we've done' there has to be more work to empower Aboriginal communities rather than say we're open for dialog" (Executive teacher). It comes as no surprise that this his school did not have a Reconciliation Action Plan, which is something most institutions in Australia now have. However, it did have a broad statement about acknowledging the wrongs of the past. Without the focus of a RAP and clear leadership in this area, the school culture was clearly not driving Reconciliation as a priority, and it was left up to individual teachers to find resources and find where they can embed IHC into their curriculum. The findings show that this was proving to be largely ineffective

\subsection{School B}

In School B the evidence was that teachers were much more active in how they discussed implementing IHC into their curriculum. However, at the time of the interviews the new WA curriculum had not yet been fully implemented. As a result, there was only one content descriptor in the WA curriculum in Year 10 which was one of the few places to include IHC and teachers chose to focus on the Cold War instead. "Yes, we've done most of it but we haven't done the Civil Rights part and Freedom Rides was an option as an assessment but most of them chose the Cold War. But next year it will become an integral part of the whole thing" (Teacher). When asked to explain why the Cold War was chosen over Rights and Freedoms the teacher responded, "Probably because that's where the focus probably was from a teaching point of view I would say" (Teacher). Therefore, the Cold War was easy to teach as not only did it follow on from WW2 but also they had plenty of resources for it. "A lot of resources and would also looked at World War II so the Cold War lent itself as the next step" (Teacher).

This pattern was highlighted by one teacher who discussed the ease in which IHC particularly the CCP could be left out of the curriculum. "If it's not clearly specified in the syllabus and left up to the individuals, it might be a bit more hit and miss in what's covered and what's not" (Teacher). However, another teacher at the school found places in Civics and Citizenship, a unit in Year 8, where they could discuss rights. This was led by the teacher who chose to use the descriptor which looked at laws and how they impacted on Indigenous people and their customary law. "I mean the stuff I mentioned before about doing the case study on Indigenous rights, there was nothing in the curriculum about that. I just got a good opportunity" (Teacher). As the school, along with the curriculum, encouraged embedding IHC rather than making it a standalone unit, this meant that there were no or few places for its implementation to be checked.

"Given the time we have left in the term and what we've got to cover it would probably only be a few lessons. So it certainly is not whole units or anything like that. It's part of a bigger picture that sort of fits in with what I was saying about how we got away 
from big units on themes like that, to incorporating Indigenous history or aspects of indigenous culture where they are relevant" (Teacher).

The Executive teachers at the school were certainly aware that IHC was being implemented in HASS and English because it was stated in the documented curricula. However, it was not so for other subject areas. "Not many, and it's certainly not integrated across other learning areas" (Executive teacher). However, another Executive teacher suggested that it was implemented in areas such as Sport and Art. However, the Executive teachers were less clear on if IHC was being implemented in Science, Maths and IT. Teachers were therefore trusted to be embedding IHC into their units. This was an issue for teachers as the curriculum included a large amount of content which teachers struggled to get through.

Students confirmed the fact that although IHC was taught in the school it was mainly in HASS and English but even then it wasn't necessarily a focus. "Yeah, since we have that Australian aspect every year, it might sometimes pop in. Then it's like we might discuss this for a little bit but it's not focused on" (Student). When asked if it was taught in any other subjects they answered 'no' which suggests that even if it was taught, the emphasis wasn't memorable for these students. It was then not surprising when they talked about a big gap in their knowledge of Indigenous perspectives in their understandings of Australian history. "So there's kind of a big gap there. Yeah, I think like from settlement to now, like we missed out a lot of what happened there. I'm not really sure of what happened. Yeah so it would be good to learn about that" (Student).

All the teachers interviewed, spoke about the school culture and the recent push to make IHC a more visible part of the school. This was evidenced in acknowledgment of Country at assemblies which was conducted by the few Indigenous students at the school. Although the number of students was very small compared with the rest of the population of the school, it was evident that everyone was aware of the new focus.

One Executive teacher discussed how he went about implementing a RAP, "I still remember, I sent an email off to the staff and I said, look I'd like put together a reconciliation action plan, if you're interested could you please come to a meeting at 7 o'clock in the morning on such and such a day. I had 32 people turn up" (Executive teacher). This interest in Reconciliation and understanding of the schools role and individual role, was echoed by a Lead Teacher who said, "I think it was more about how can we, as a college can be considering [Reconciliation] within our own teaching and learning but also in the wider college and in the community, what are we doing". Even if teachers weren't implementing the $\mathrm{CCP}$ as was intended by the curriculum it was clear that the School culture encouraged promoting Reconciliation within the school in other ways. This included at assemblies or inviting Indigenous students to the school from the metropolitan area as well as from Indigenous communities from the north of the state.

Nevertheless, despite this headway students still were not happy with the small amount of IHC they were explicitly taught. As the RAP was still a recent adoption from the school it may need more time before the school culture catches up and IHC is embedded more thoroughly throughout.

\section{Discussion}

The teaching of IHC is complex, because although it is stipulated by the Melbourne Declaration and included in two teaching standards, it is still easy to avoid. To have IHC embedded across all learning areas implies that students will be exposed to IHC throughout their school.

Despite this, the evidence from the two schools show that IHC has not been a priority in the WA curriculum as the CCP are not prioritised within the curriculum. It was evident in both School A and B that the inclusion and embedding of IHC was left up to the individual teacher to implement, with the outcome that very little emphasis was given to it.

The findings also revealed that school leadership played an important role in whatever priority IHC was given within the school. It was clear that from School A there was hardly any emphasis placed on IHC by Executive teachers for the stated reason that they had few Indigenous students. Their view of Reconciliation focused more on empowering Indigenous communities outside the school, rather than what the school could be doing to educate its students towards Reconciliation.

On the other hand, School B, despite also having few Indigenous students, chose to make promoting IHC a part of the school culture. This was achieved through the inclusion of IHC at assemblies and the Indigenous students they did have becoming more visible in the school. The school also was in the process of renewing their RAP with their recently appointed AIEO, another initiative led by the Executive.

Although both schools stated that it was part of their school culture to promote Reconciliation and IHC to, HASS and English were the only learning areas where it was explicitly taught in both schools. An Executive teacher from School B suggested it was taught in other subject areas; however, the students from the focus group could not remember being taught IHC outside of HASS and English. There was evidence from both schools that there were places where IHC could be implemented; however, it was the individual teacher who had to 
find this place. Therefore, the teaching of IHC was dependent on the teacher's interest and push for its implantation.

Yet, the students interviewed from both School A and School B discussed their lack of knowledge of IHC. They specifically stated that they had learnt about Settlement and the Stolen Generation and nothing in between. In School B, the teachers believed IHC was embedded and that they were doing a good job in embedding them but this evidence shows that this was clearly not the case. Furthermore, the students were obviously interested in the history of Australia and the role of Indigenous peoples in that history and felt they weren't getting enough. This was mirrored in School A; the students rued missing knowledge in the same period of history. This 'missing period' of the Australian history taught in both schools was incidentally a time period of destructive government policy where Indigenous people were not counted as citizens and the government controlled who they could marry, where they could go and where they could live.

The emphasis placed on Reconciliation was largely placed in the hands of the school's Executive teachers. The confusion in the role the school played in promoting Reconciliation filtered down to the teachers who decided when and if it was to be implemented outside of units explicitly including IHC. However, although there was still gaps in student education within HASS and English and across learning areas in both schools; it was clear that in School B was putting effort into promoting Reconciliation throughout the school even if it wasn't explicit in the curriculum. This was a top down decision from Executive teachers.

\section{Conclusion}

In the teaching of IHC there is a filtering of importance and priority given from the Melbourne Declaration, through the Australian and WA Curriculum to the enacted curriculum. To further explain, the Melbourne Declaration as the curriculum of entitlement, is explicit as it states the importance of all Australian children learning and benefiting from Reconciliation. This is then filtered through the curriculum of intent in the form of the Australian and WA curriculum. It is no longer explicitly included in units across HASS, English and any other learning area, instead it is to be embedded throughout every learning area. As many teachers have few resources for IHC and little background knowledge, it could be overlooked in favour of more easily implemented topics with tried and tested resources.

Yet, IHC is not fated to be drizzled across the curriculum with the hope that it finds a crack to fill. School culture can provide a much more proactive place for IHC so it is not just left up to individual teachers but a concerted effort by all departments and staff led by the Executive teachers of the school. Therefore, the enacted curriculum can be far more inclusive of IHC if the school culture promotes and supports it. The received curriculum in terms of IHC from both schools was very little. However, if IHC is celebrated outside of the classroom and acknowledged regularly the school becomes an institution which values IHC. A value which the student will take away with them into the wider community.

From this study, it was clear that school culture was what was driving the teaching of IHC at both schools. Teachers across the schools acknowledged that CCP could be avoided. This was particularly the case because the Australian and WA Curriculum included so much content that teachers struggled to get through it. However, school culture and school leadership therefore, played a large role in implementing IHC into the school community. The attitudes of the leaders of both schools clearly differed.

Yet, the students from both schools still believed they were missing out of vital knowledge about their country's past. Simply being aware of IHC was not enough for the students interviewed and they believed that their schools could be doing more. It may have been too early to see the change which was being developed by the leadership yet, with the content levels of the curriculum overflowing and IHC only needing to be implemented where relevant there is a real danger of students leaving school with little knowledge of IHC. This will hamper efforts to continue the nation moving towards Reconciliation is students are missing vital information about what has led to Indigenous disadvantage. And these students want to know, they're eager to learn.

One factor which arose from this study from everyone who participated, was the importance of teaching for Reconciliation. Yet, in order to do so, teachers need to be supported and encouraged and reminded that teaching Indigenous cultures and histories is important for all students.

Reconciliation is an ongoing process which needs contributions from both Indigenous and nonIndigenous Australians to continue to progress. Education is a powerful player in this process and therefore, to understand how schools are teaching Indigenous perspectives could be useful in the progress of Reconciliation. The priority schools give Reconciliation seems dependent on leadership from the principal or a champion to drive it. However, with the increasing demands on teacher's time, it appears that there is little incentive for those that were interviewed to step forward for this role. 


\section{References}

[1] Australian Institute for Teaching and School Leadership. Australian Professional Standards for Teachers. 2017 [cited 2017 August].

[2] AGDSS. "Closing the Gap: The Indigenous Reform Agenda." Australian Government Department of Social Services, http://www.dss.gov.au/ourresponsibilities/indigenous-australians/programsservices/closing-the-gap.

[3] Australian Government Department of the Prime Minister and Cabinet, "Chapter two Education: School attendance target, Literacy and numeracy target, Year 12 Attainment target" Retrieved: Jan 2017

http://closingthegap.dpmc.gov.au/chapter-02/index.html

[4] Balvin, Nikola, and Yoshihisa Kashima. "Hidden Obstacles to Reconciliation in Australia: The Persistence of Stereotypes." In Peace Psychology in Australia, 197219: Springer, 2012.

[5] Banales, Josefina. "The Sustained Impact of an Engaging Diversity Program on College Seniors' ColorBlind Racial Attitudes." CrissCross 2, no. 1 (2014): 1.

[6] Blumer, Herbert. Symbolic Interactionism: Perspective and Method. Los Angeles: University of California Press, 1969.

[7] Case, Kim A. "Raising White Privilege Awareness and Reducing Racial Prejudice: Assessing Diversity Course Effectiveness." Teaching of Psychology 34, no. 4 (2007): 231-35.

[8] Cavanagh, Paddy. "Discovering Shared History: Moving Towards New Understanding in Australian Schools." In Teaching Aboriginal Studies: A Practical Resource for Primary and Secondary Teaching, edited by Rhonda Craven, 110-31. Crows Nest: Allen \& Unwin, 2011.

[9] Donnelly and Wiltshire, Review of the Australian Curriculum. Final Report, E. Department, Editor. 2014, Australian Government Department of Education and Training.

[10] Harrison, Dan. "Changes Ahead for History." WAtoday (2008). Published electronically September 19, 2008.http://www.watoday.com.au/execute_search.html?tex $\mathrm{t}=$ Dan+Harrison\&cat=Education\&sortBy=lastpublisheddat e\&order=ASCENDING\&ss=watoday.com. au\&view=medi a.

[11] Kalantzis, Mary. "The Cultural Deconstruction of Racism: Education and Multiculturalism." Sydney Studies in Society and Culture 4 (2013).

[12] School Curriculum and Standards Authority. CrossCurriculum Priorities. 2014 [cited 2017 August]; Available from: https://k10outline.scsa.wa.edu.au/hom e/teaching/cross-curriculum-priorities $2 /$ cross-curriculumpriorities.
[13] Smith, David, Lovat and Terence. Curriculum: Action on Reflection. Sydney: Social Science Press, 2003.

[14] Maxwell, Jacinta. ""It's a Bit Hard to Tell, Isn't It": Identifying and Analysing Intentions Behind a CrossCurriculum Priority." Curriculum Perspectives 34, no. 3 (2014): 27-38.

[15] MCEETYA. "Melbourne Declaration on Educational Goals for Young Australians." edited by Employment Ministerial Council on Education, Training and Youth Affairs. Melbourne: Curriculum Corporation as the legal entity for the Ministerial Council on Education, Employment, Training and Youth Affairs (MCEETYA), 2008.

[16] Reconciliation Australia. "Reconciliation Action Plan 2008-2013." Horizon Power Reconciliation Action Plan 2008-2013, 2013.

[17] Reconciliation Australia. "The State of Reconciliation in Australia Summary." Kingston: Reconciliation Australia, 2016.

[18] Reynolds, Henry. Why Weren't We Told?: A Personal Search for the Truth About Our History. Penguin Books, 2000.

[19] Rose, Mark. "The 'Silent Apartheid' as the Practioner's Blindspot." In Aboriginal and Torres Strait Islander Education: An Introduction for the Teaching Profession, edited by Kaye Price, 64-80. Sydney: Cambridge University Press, 2012.

[20] Sarra, Chris. Strong and Smart: Towards a Pedagogy for Emancipation: Education for First Peoples. London: Routledge, 2011. 